\title{
Valor dos métodos de diagnóstico por imagem na avaliação das reações/fraturas de estresse ${ }^{(*)}$
}

\author{
The value of the image diagnosis methods \\ in the evaluation of reactions/stress fractures
}

\author{
André Yui Aihara ${ }^{(1)}$, Artur R. Correa Fernandes ${ }^{(1)}$, Jamil Natour ${ }^{(2)}$
}

\section{INTRODUÇÃO}

O termo fratura por estresse é usado para descrever fraturas que ocorrem após estresse repetitivo insuficiente para causar uma fratura aguda ${ }^{(1,2,3)}$.

São reconhecidos dois tipos de fratura por estresse: fratura por fadiga, que resulta de estresse anormal em um osso normal; e fratura por insuficiência, que ocorre quando há estresse normal em um osso com resistência elástica ou conteúdo mineral deficiente ${ }^{(1,2,3)}$.

As fraturas por fadiga geralmente compartilham das seguintes características: a atividade é nova ou diferente para a pessoa, ou a atividade é extenuante ou é repetida com uma freqüência que acaba resultando em sintomas ${ }^{(1)}$. Outros fatores associados são treinamento inadequado, calçado inadequado, superfície imprópria para a corrida, estilo de corrida, mau alinhamento biomecânico, início de um programa de treinamento ou troca para programa mais extenuante ${ }^{(4)}$.

As fraturas de fadiga podem ocorrer também após alguns procedimentos cirúrgicos como para hálux valgo (metatarsos), prótese de quadril (ramo púbico), ou cirurgia do joelho(3).

As causas de fratura por insuficiência são várias e incluem artrite reumatóide, osteoporose, doença de Paget, osteomalácia e raquitismo, hiperparatireoidismo, osteodistrofia renal, osteogênese imperfecta, osteopetrose, displasia fibrosa e irradiação ${ }^{(2,3)}$.

Os locais mais comumente acometidos pela fratura por estresse são as porções média e distal do $2 .^{\circ}$ e $3 .{ }^{\circ}$ metatarsos, tíbia proximal, calcâneo, metáfise proximal ou distal da fíbula (principalmente distal) e a pars interarticularis da coluna lombar baixa associada ou não com espondilolistese ${ }^{(3)}$.

Estas fraturas representam até $20 \%$ das lesões em medicina esportiva, a maioria ocorrendo em corredores, mas também praticantes de outros esportes e academia. Mulheres têm incidência 1,5 a 3,5 vezes maior que em homens ${ }^{(4)}$.

\section{$\overline{\text { DIAGNÓSTICO CLÍNICO }}$}

Os achados clínicos das fraturas de estresses são característicos.

Tipicamente a dor é relacionada com a atividade e é aliviada com o repouso. Observa-se edema de partes moles e dor localizada sobre a área da fratura de estresse. Quase todos os ossos podem ser afetados, sendo os ossos dos membros inferiores mais freqüentemente acometidos ${ }^{(3)}$.

Nos casos de fratura por fadiga, no início, a dor não está presente no começo mas sim mais para o final do exercício $^{(4)}$. Com a evolução do problema, há dor em todo o exercício e deambulação ${ }^{(4)}$.

\section{DIAGNÓSTICO POR IMAGEM}

O Rx tem papel essencial no diagnóstico da fratura de estresse, porém muitas vezes não apresenta alterações, principalmente nos casos precoces ${ }^{(1,4,5)}$. As alterações ósseas geralmente não são evidentes ao Rx por 10 a $21 \operatorname{dias}^{(2,5,6)}$.

\footnotetext{
* Departamento de Diagnóstico por Imagem (DDI) da Universidade Federal de São Paulo (UNIFESP).

1. Departamento de Diagnóstico por Imagem (DDI) da Universidade Federal de São Paulo (UNIFESP). Laboratório Delboni Auriemo.

2. Disciplina de Reumatologia da UNIFESP.
}

Endereço para correspondência: Artur da Rocha Correa Fernandes. Departamento de Diagnóstico por Imagem (DDI) da Universidade Federal de São Paulo (UNIFESP). Rua Botucatu, 740, CEP 04023-900, São Paulo, SP, Brasil. 
Na prática, as radiografias iniciais são negativas em dois terços dos casos, sendo que apenas metade desenvolve alteração radiográfica visível no controle evolutivo ${ }^{(4,6)}$.

Quando positivos os raios-X podem demonstrar linha cortical de fratura, bandas irregulares densas de neoformação óssea ${ }^{(5)}$, reação periosteal, espessamento cortical ou endosteal, ou uma combinação destes achados ${ }^{(3)}$.

A tomografia computadorizada pode ser útil na demonstração do traço de fratura $^{(3)}$, através da caracterização de discretas descontinuidades da cortical, reações periosteais ou tênues linhas de esclerose óssea (que representam fraturas em evolução ).

A cintilografia com Tc-MDP permite detecção precoce (a partir de 24 horas), mostrando áreas focais de aumento moderado ou intensode concentração do radiofármaco ${ }^{(1,5)}$.
No entanto, a cintilografia têm sido substituída pela ressonância magnética (RM), em razão da sensibilidade comparável e especificidade superior desta última ${ }^{(1)}$.

$\mathrm{Na}$ RM as fraturas de estresse clássicas se caracterizam por zonas lineares de hiposinal em T1 e hiposinal ou hipersinal em T2 (traduzindo microfraturas trabeculares ou esclerose óssea), circundada por uma zona mal definida de hiposinal em T1 e hipersinal em T2 caracterizando edema ósseo ${ }^{(1,2,5)}$. Eventualmente a RM pode demonstrar áreas focais justacorticais ou subperiosteais de hipersinal em $\mathrm{T} 2^{(5)}$.

Os principais diagnósticos diferenciais das fraturas de estresse são: osteoma osteóide, osteomielite, osteosarcoma, necrose isquêmica, fratura oculta e linhas de parada de crescimento $^{(3,5)}$.
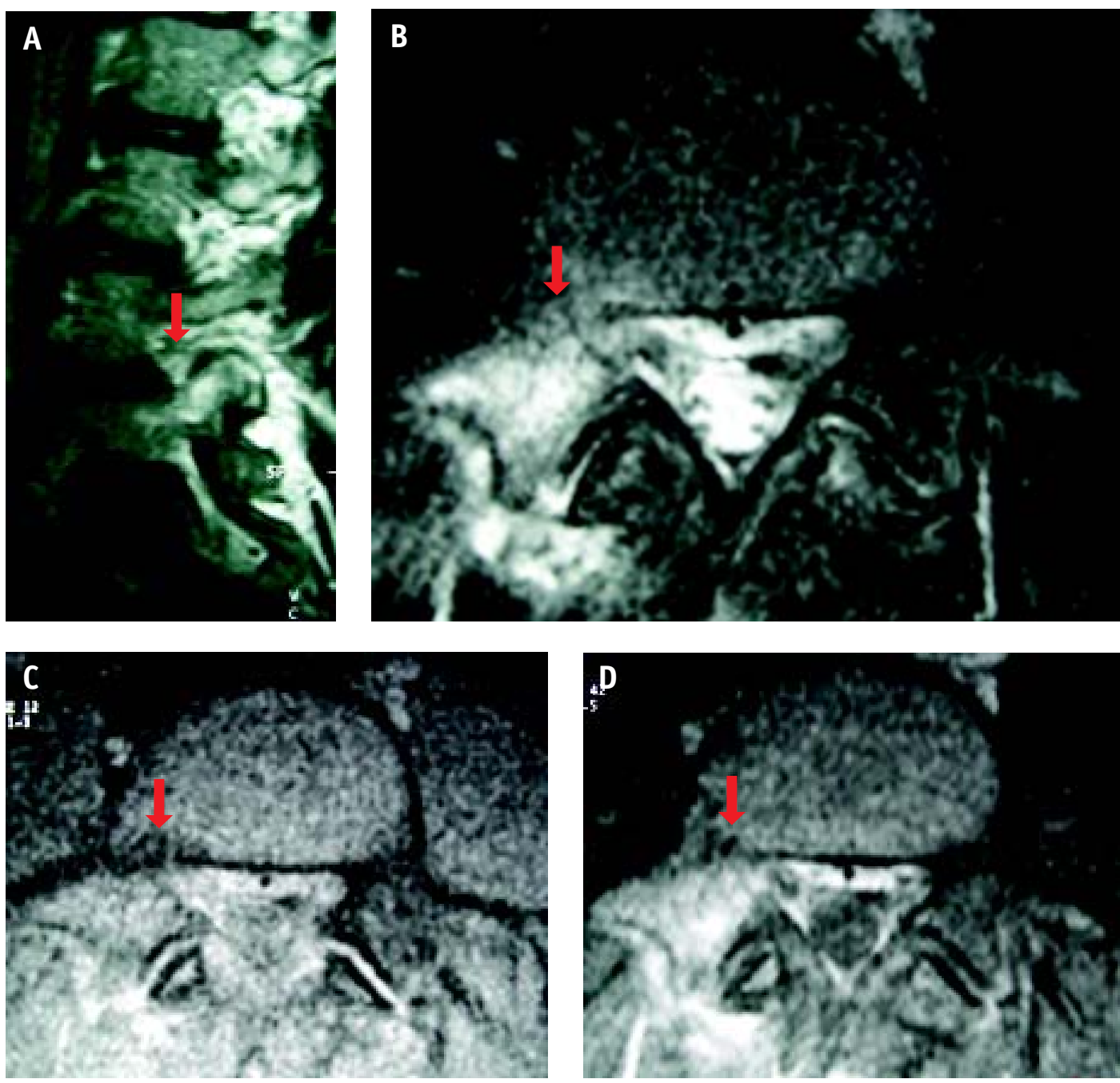

Figura 1 - RM de coluna lombosacra. A) Sagital e axial T2 mostran do hipersinal da pars articularis à direita. C e D) Axial T1 com supressão de gordura pré e pós con traste evidenciando realce, caracterizando edema/processo inflamatório. 

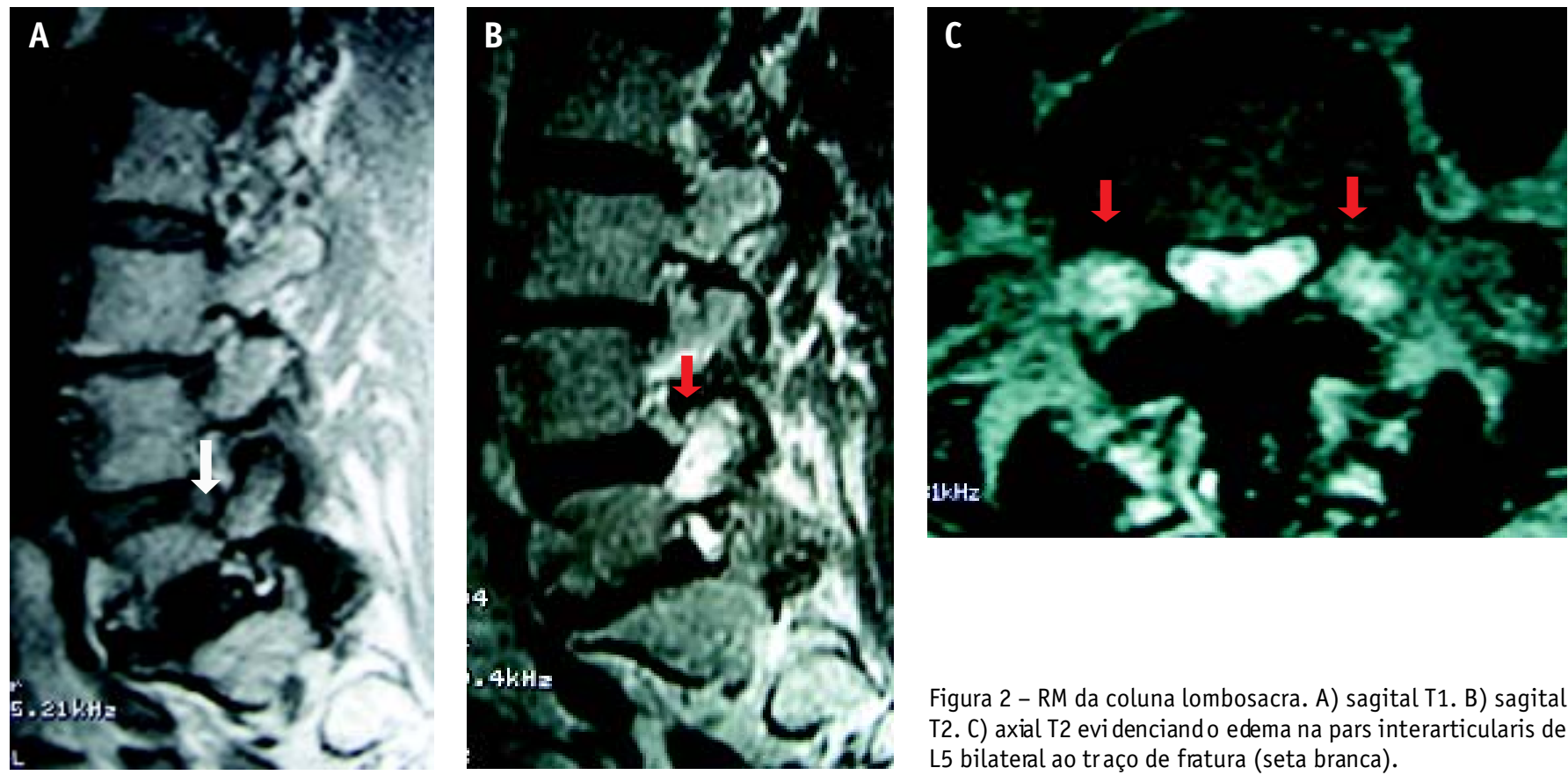

Figura 2 - RM da coluna lombosacra. A) sagital T1. B) sagital T2. C) axial T2 evi denciand o edema na pars interarticularis de L5 bilateral ao traço de fratura (seta branca).
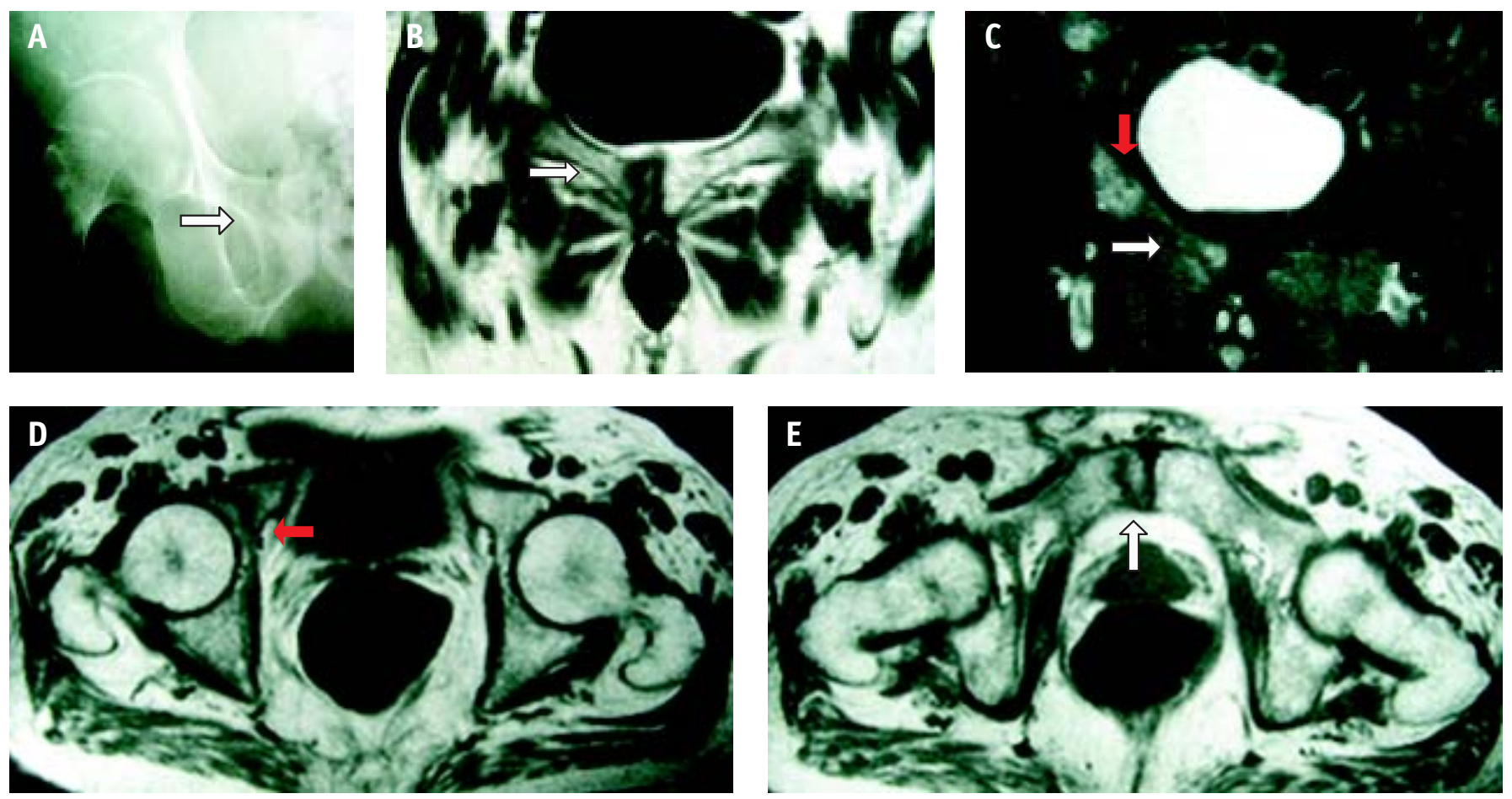

Figura 3 - Mulher, 71 anos, com osteoporose e dor no quadril dir eito sem história definida de trauma. A) Rx dem onstrando tênue traço de esclerose óssea. B) RM coronal T1 mostrand o traço de hiposinal (fratura). C) RM coronal STIR mostran do edema ósseo na sínfise púbica e na coluna anterior do acetábulo. D e E) RM Axial T1 mostrando traço de fratura na coluna anteri or do acetábulo e no púbis a direita. 

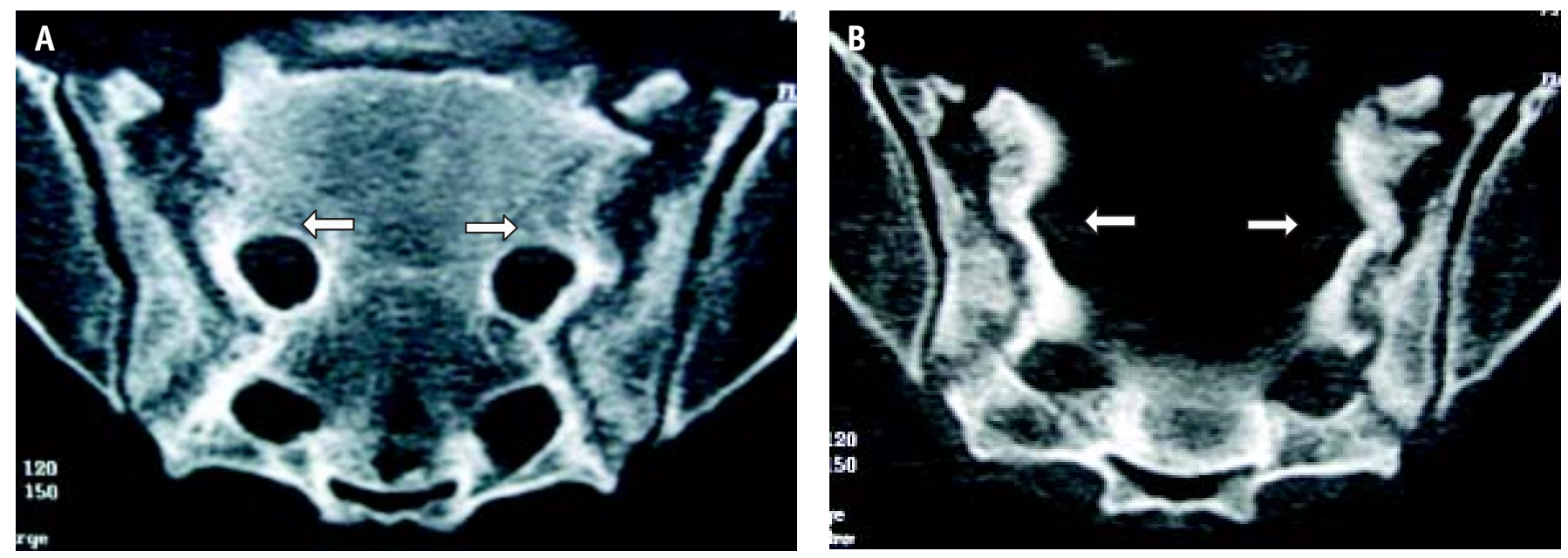

Figura 4 - Mulher, 76 anos, história de d or sem trauma definido. A e B) TC coronal e axial m ostrand o fratura exten sa bilateral.
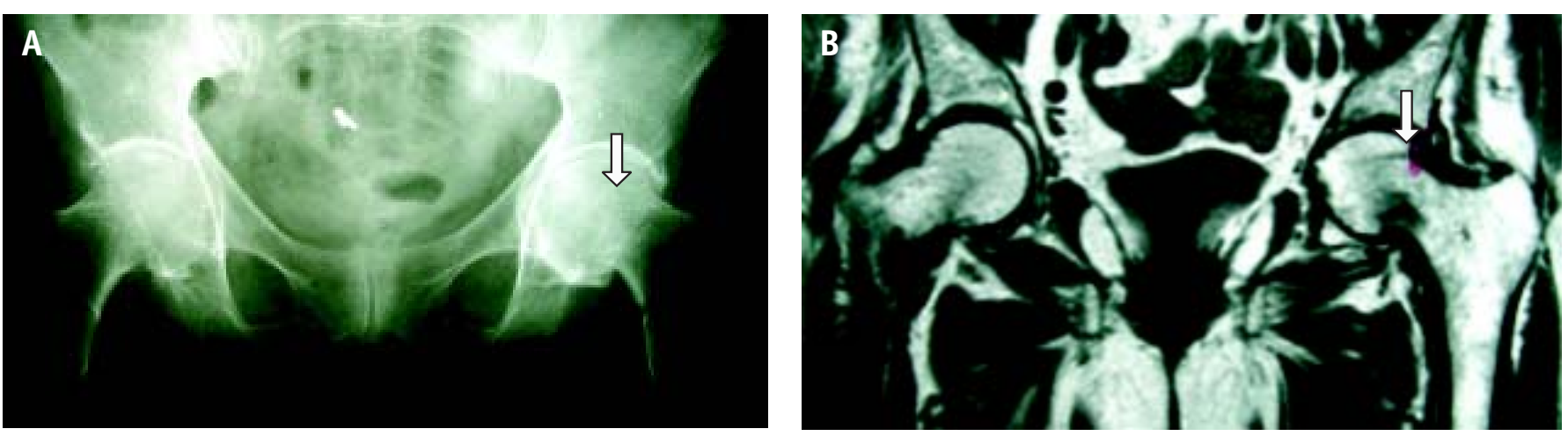

Figura 5 - Mulher idosa, com dor no quadril esquer do. A) Rx evidencian do discreto traço de esclerose no colo femoral. B) RM demontrando com mais clareza tal alteração.
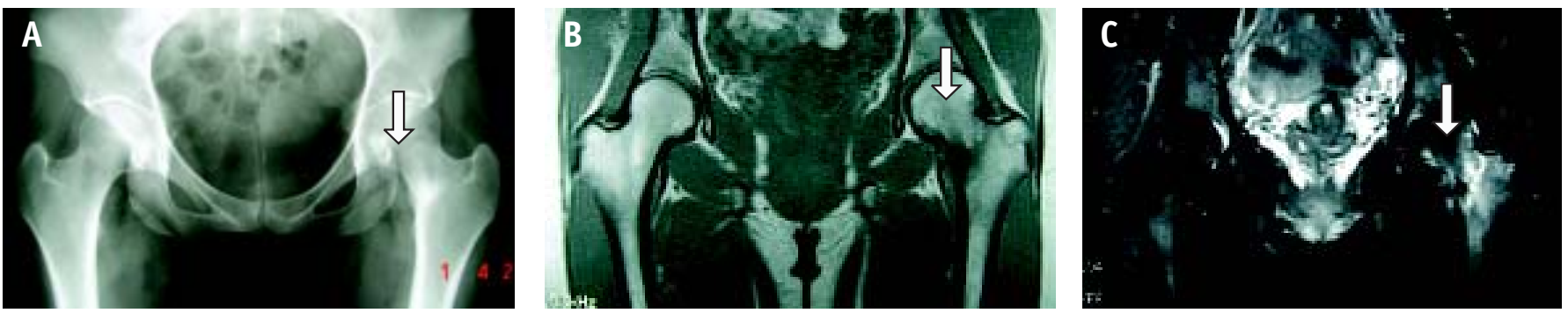

Figura 6 - Mulher, 24 anos, pratican te de esporte em academia 4 vezes por semana que passou a apresentar dor no quadril esquerdo. A e B) Rxe RM coronal T1 mostran do foco de escler ose óssea no colo femoral. C) RM coronal STIR mostrando área de escler ose óssea circun dada por edema. 
Figura 7 - Paciente feminina de 26 anos com dor no joelho. Paciente faz esporte em academia e passou a sentir dor após iniciar spinning. A e B) RM coronal T1 e T2 evidenciando pequeno foco de hiposinal em T1 e STIR (fratura), circunda do por halo de edema medular ósseo.
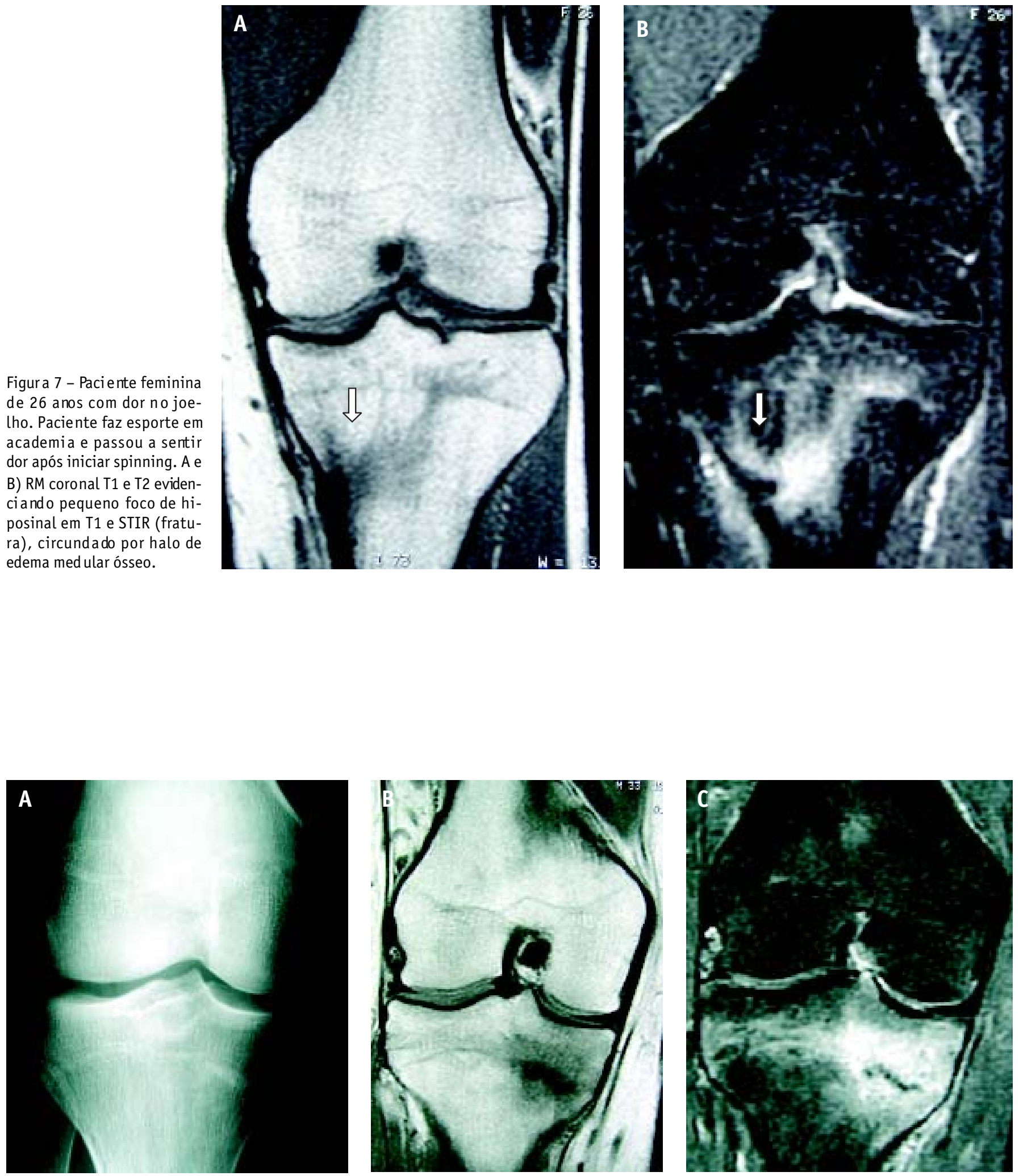

Figura 8. Paciente masculino de 33 anos. A) Rx evidencia ndo traço de esclerose óssea na região metaepifisária medial da tíbia proximal. B e C) RM coronal T1 e STIR d emonstrando traço de hiposinal compatível com fratura, circun dado por edema ósseo. 

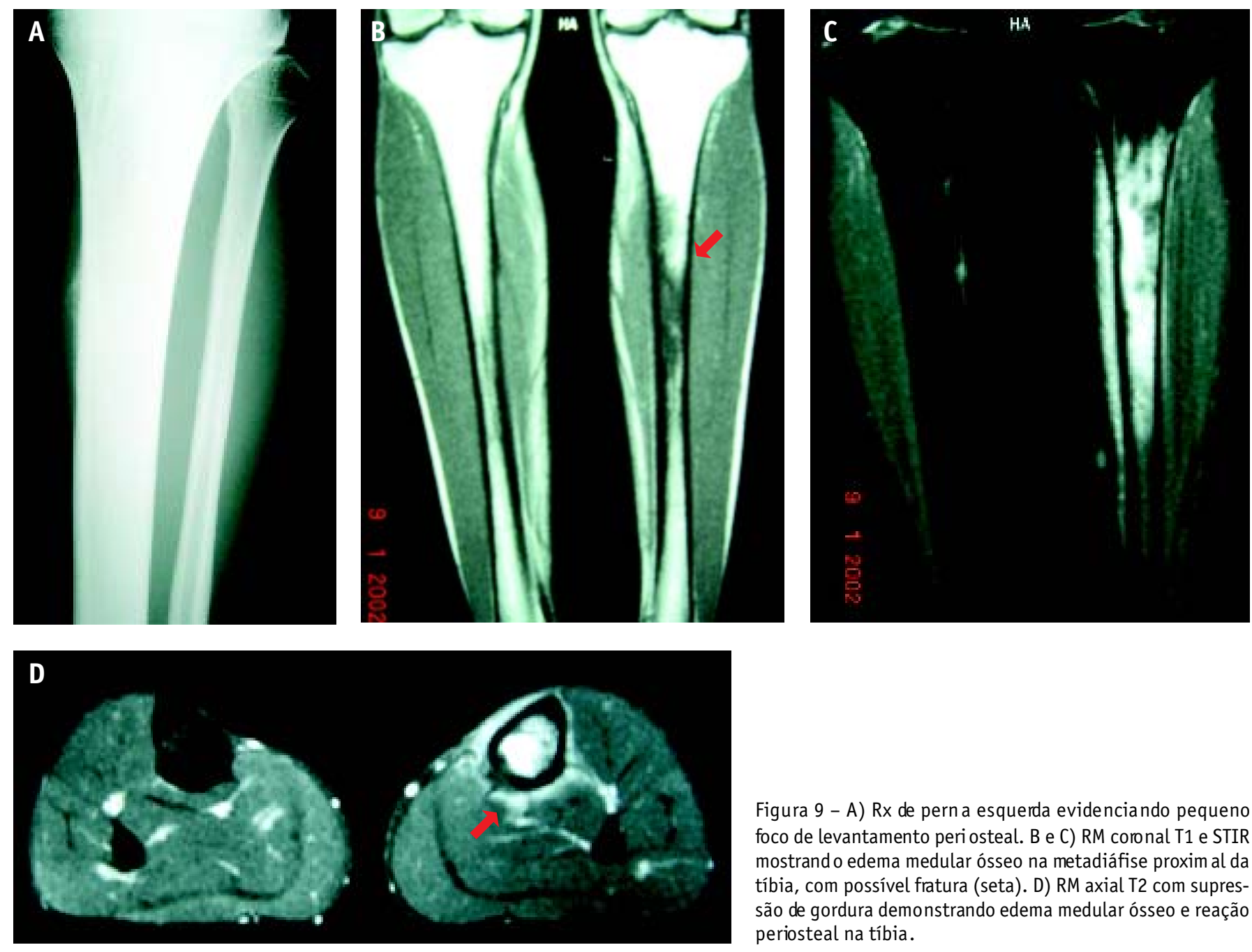

Figura 9 - A) Rx de pern a esquerda evidenciando pequeno foco de levantamento peri osteal. B e C) RM coronal T1 e STIR mostrand o edema medular ósseo na metadiáfise proxim al da tíbia, com possível fratura (seta). D) RM axial T2 com supressão de gordura demonstrando edema medular ósseo e reação periosteal na tíbia.
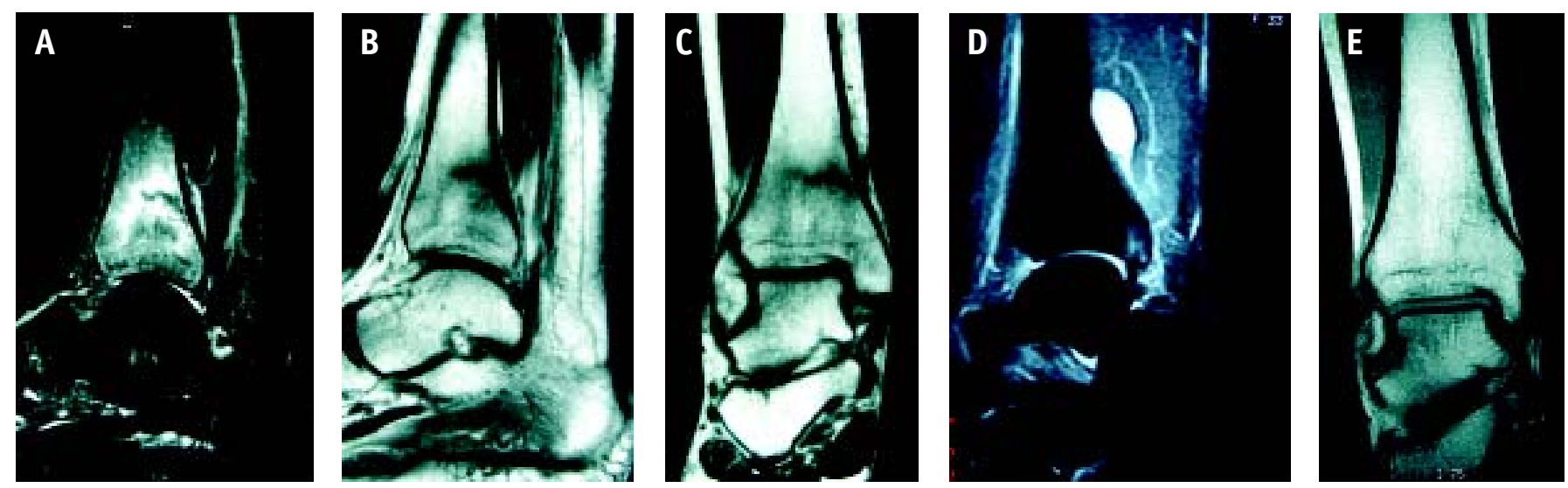

Figura 10 - Mulher, 33 anos, praticante de esporte em academia, com d or no tornozelo. A, B e C) RM sagital STIR, sagital T1 e coronal T1 mostrand o traço de fratura h orizontal m edial, circun dado por edema ósseo. D e E) RM de controle seis meses após, sem evidências de fratura ou edema ósseo, mas costrando um cisto nesta topografia. 

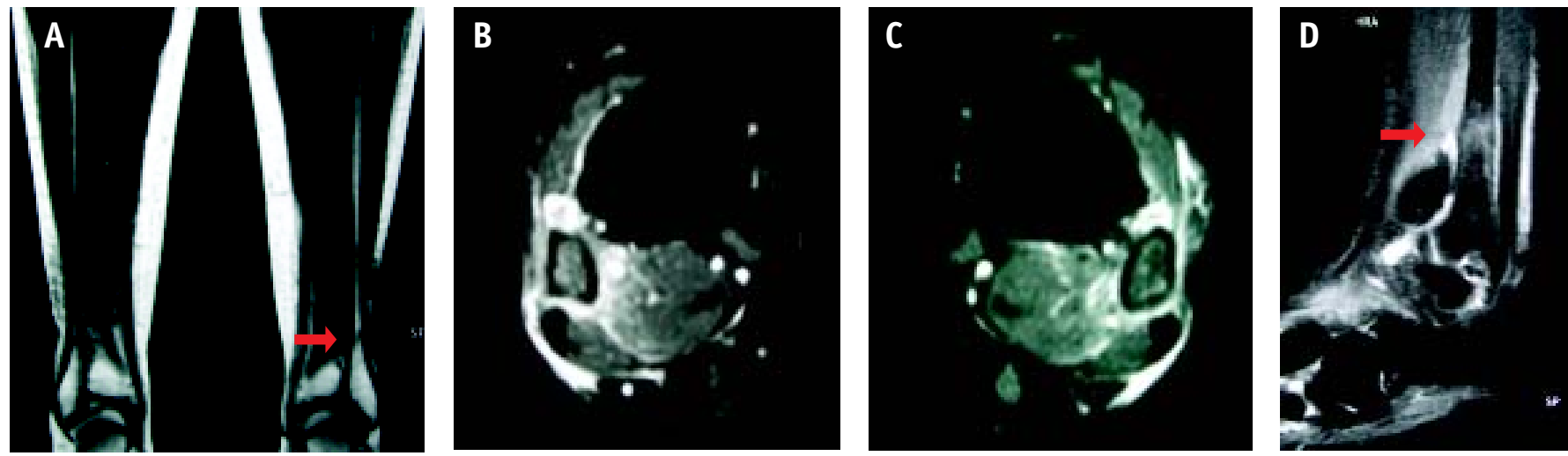

Figura 11 - Paciente do sexo feminin o, 52 anos, dor bilateral em tornozelos. Pratica caminhadas diariamente. A) RM coronal eviden cian do traço discreto de fratura na fíbula distal E. RM axial T2 com seupressão de gordura bilateral evi dencian do edema medular ósseo. D) RM sagital STIR mostrando alterações semelhantes.
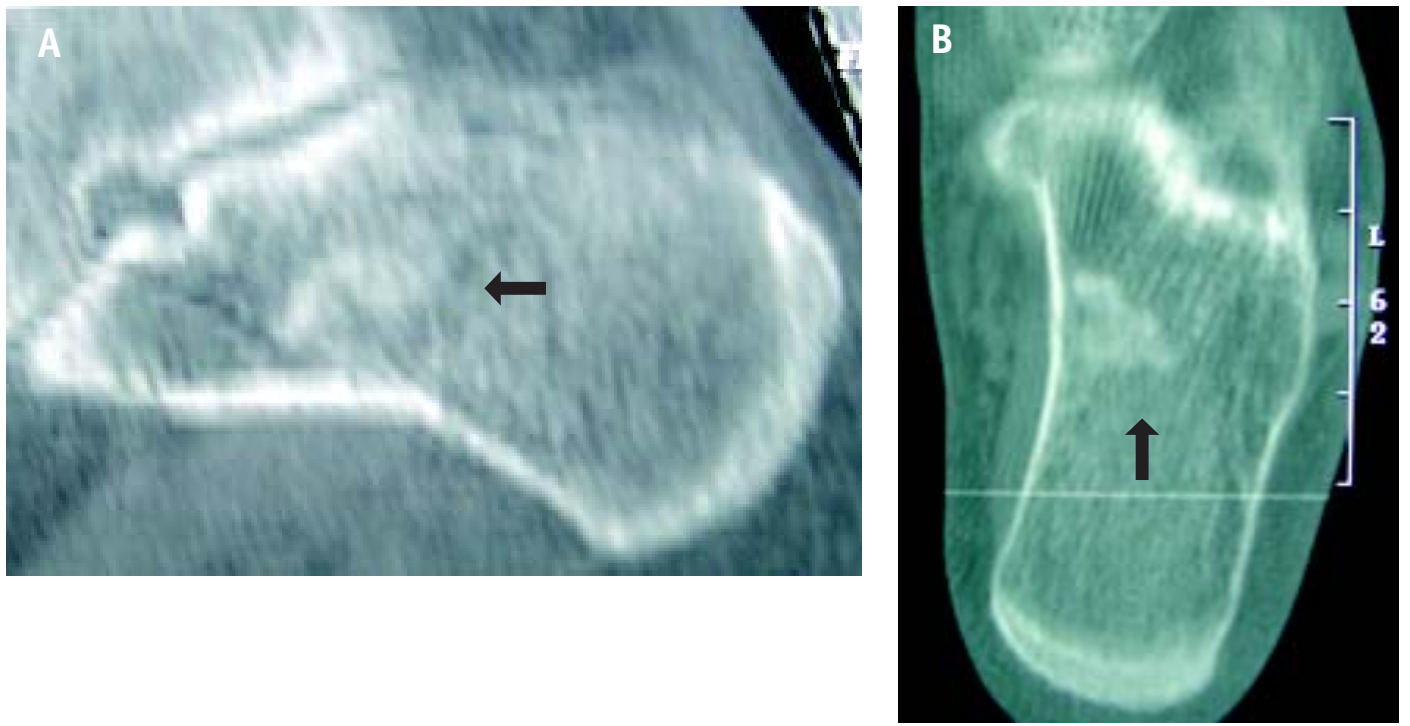

Figura 12 - Mulher, 27 anos, praticante de esportes, com dor no tornozelo, sem história de trauma. $A$ e $B$ ) TC sagital e axial. C,D e E) RM sagital T1, sagital STIR e axial T2. Traço de fratura/esclerose óssea no calcâneo.
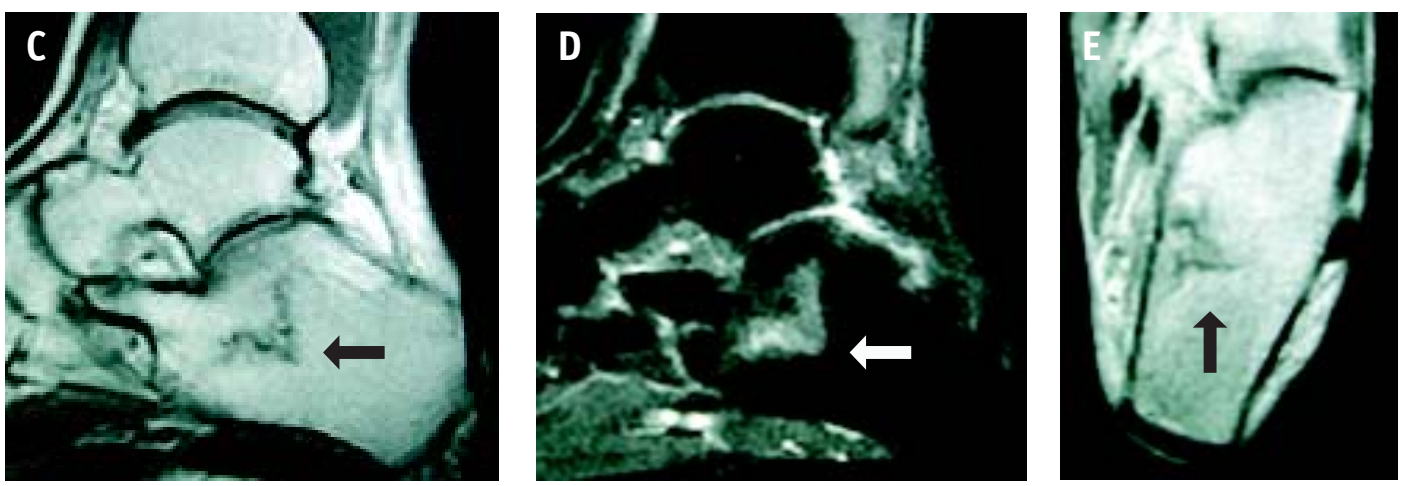

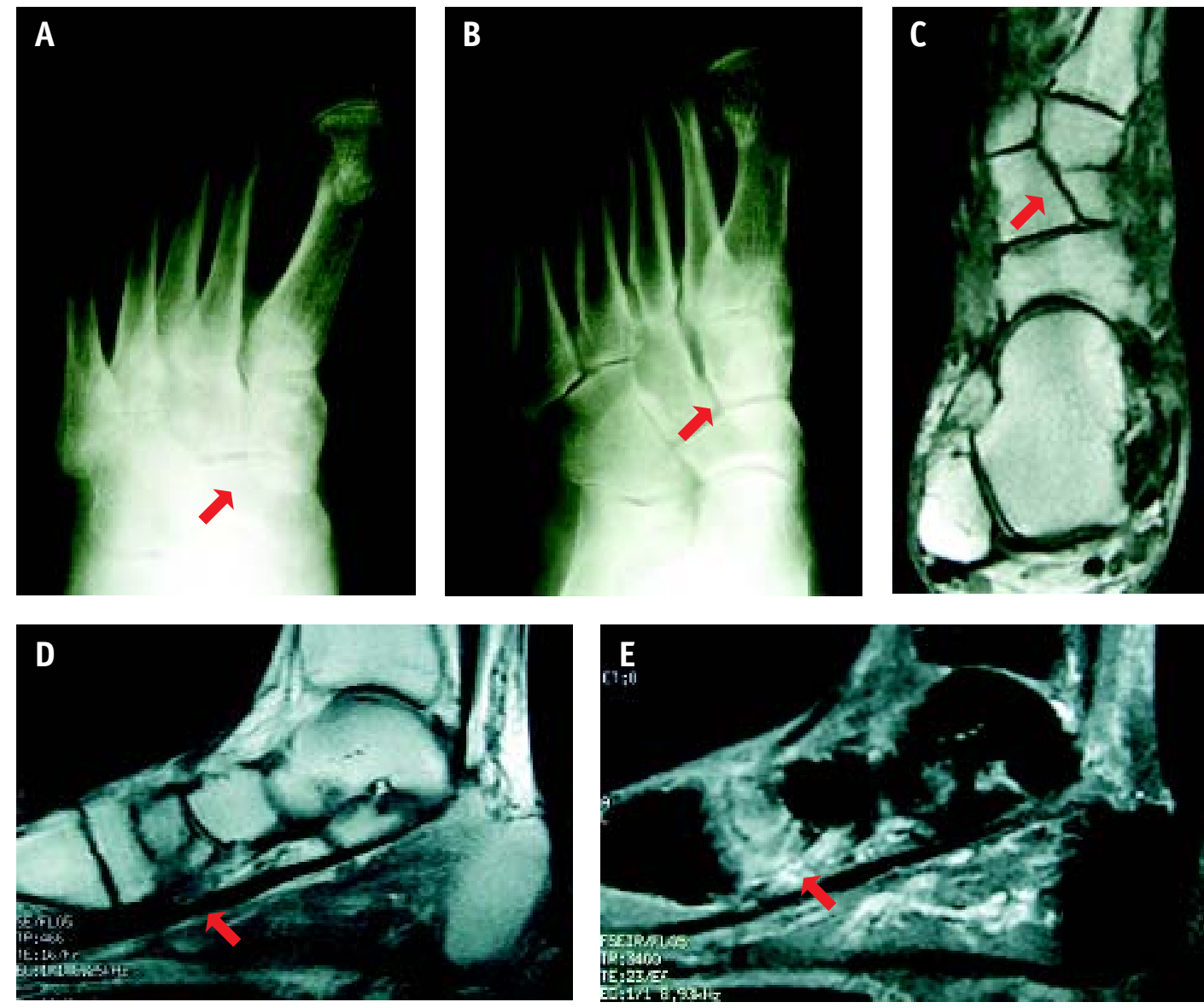

Figura 13 - Mulher de 71 anos que pratica caminhada diariamente, com quadro de dor no pé há 1 mês, sem história de trauma. Pacien te associa o início da dor com a troca de tênis que realizou pouco tempo atrás. Nota: Paciente operada de hálux valgo há 20 anos. A e B) Rx frente e oblíqua evidenciando traços de fratura/esclerose no cuneiforme medial. C, D e E) RM axial T1, sagital T1 e sagital STIR melhor demonstrand o a fratura. Em E) observamos ainda edema ósseo difuso do navicular.
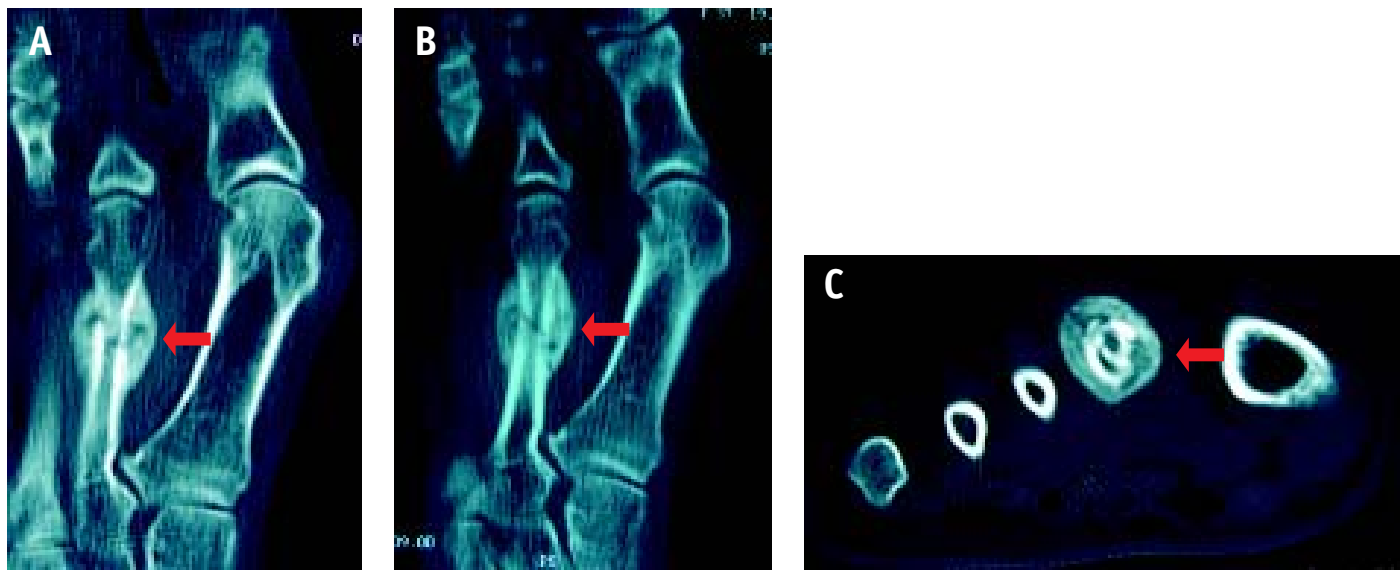

Figura 14 - Paciente feminina de 31 anos praticante de balé. A e B) TC axial demonstrando traço de fratura $n a$ diáfise do 2 metatarso, circundad o por calo periosteal. C) TC coronal eviden ciando o calo periosteal. 
Figura 15 - Pacien te masculino de 23 anos, sem história definida de trauma. A) Rx demontran do calo periosteal na diáfise do 3 metatarso. B) RM C) RM coronal STIR evidenciand o calo periosteal e edema ósseo difuso.

Figura 16 - Pacien te com dor na região dos sesamóides do 1. ${ }^{\circ}$ pododáctilo. A e B) Rx demonstra provável sesamóide medial bipartido. C, D e E) A RM mostra edema/processo inflamatório no sesamóide medial e partes moles adjate/fratur a de estresse. coronal T1. Calo periosteal. centes, sugerindo sesamoidi-
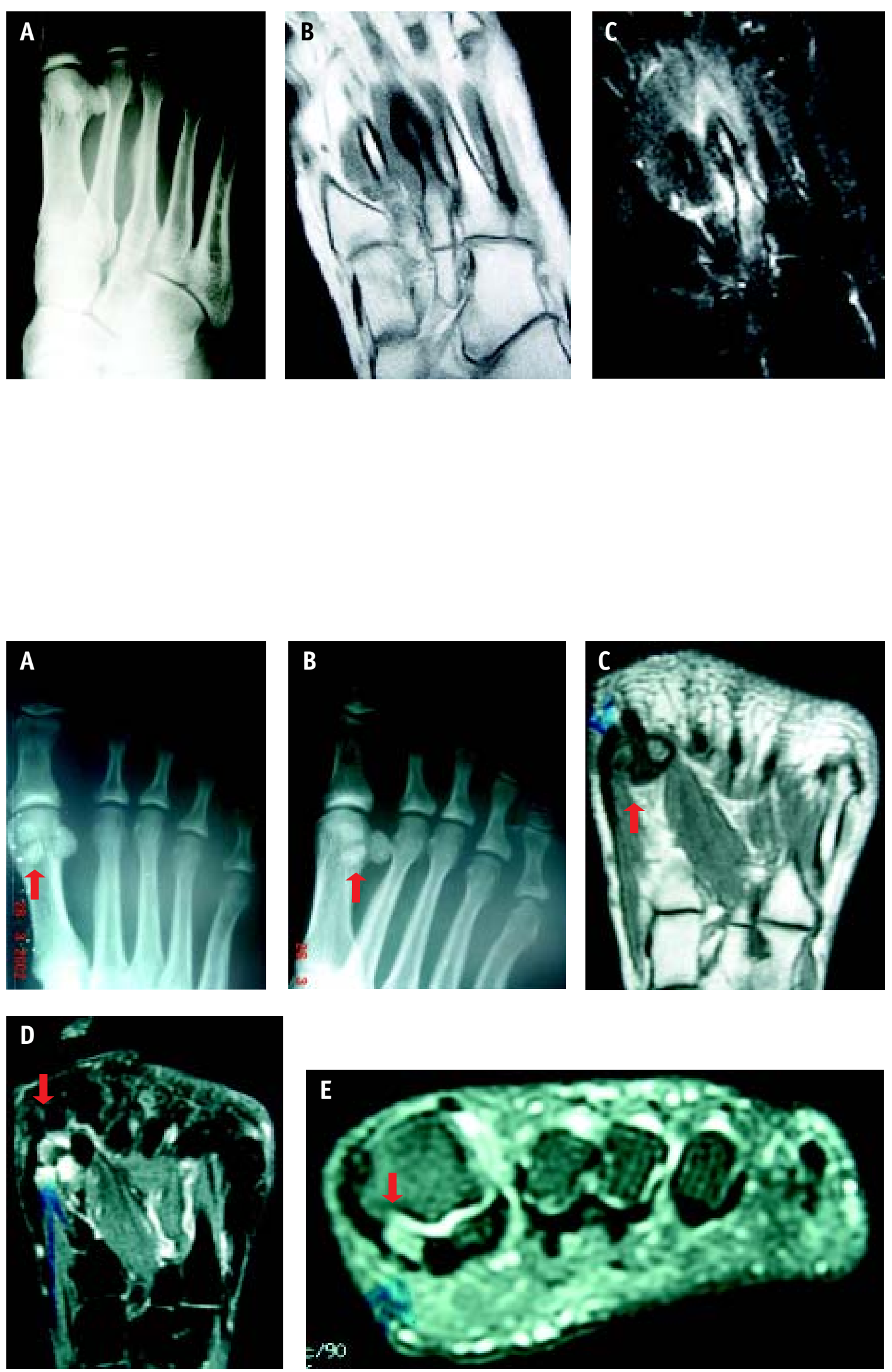

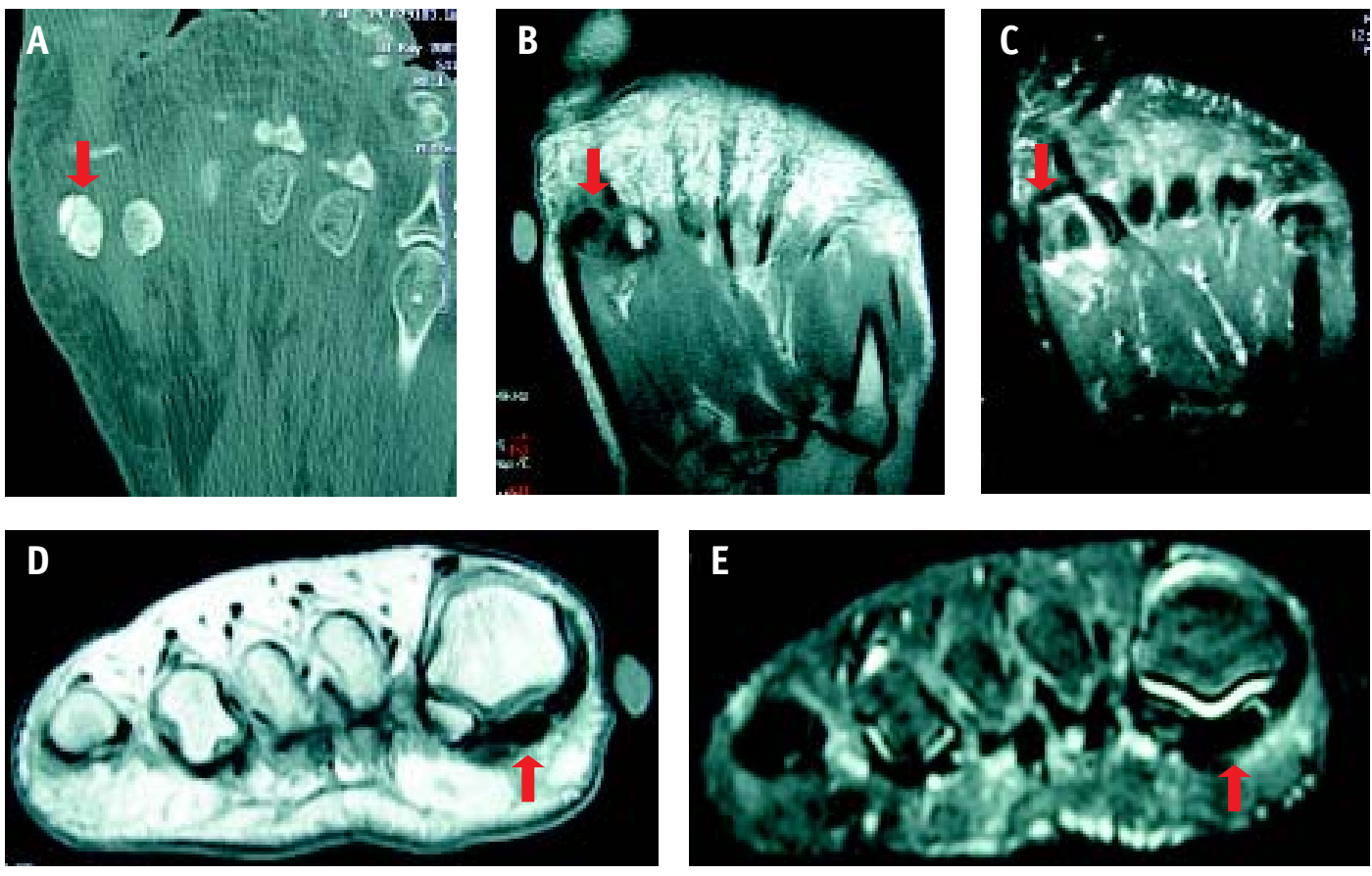

Figura 17 - Paciente feminina, 40 anos, com dor em nível dos sesamóides. A) A TC mostra sesamóide medial esclerótico com traço de fratura orientado no plano sagital. $B, C, D$ e E) A RM dem onstra a esclerose do sesamóide, além de edema/processo inflamatório adjascente.

\section{CONCLUSÃO}

No paciente com suspeita de fratura de estresse relacionada com fadiga (por exemplo, esporte) ou insuficiência (condição patológica pré-existente como AR ou osteoporose senil) deve-se iniciar com exame radiológico convencional. Se o exame for negativo, deve-se prosseguir com cintilografia óssea ou RM. Nos locais onde houver facilidade de se obter RM este será o exame de escolha após o Raio X. A TC poderá ser empregada em casos especiais para a detecção de alterações radiológicas sutis e/ou incipientes ao Raio X.
REFERÊNCIAS

1. Internal Derangements of Joints Emphasis on MR Imaging. Resnick D, Kang HS: W.B. Saunders Company Philadelphia, 1997.

2. Radiology of the Foot and Ankle. Berquist TH. Lippincott Williams \& Wilkins. Philadelphia, 2000.

3. Essentials of Skeletal Radiology. YochumTR, Rowe LJ: Williams \& Wilkins Baltimore, 1996.

4. Bergman AG, Fredericson M: MR Imaging of Stress Reactions, Muscle Injuries, and Other Overuse Injuries. in: Runners. MRI Clinics of North America 7(1):151-74, 1999.

5. Lee JK, Yao L: Stress Fractures: MR Imaging. Radiology 169:21720, 1988

6. Greaney RB, Gerber FH, Laughlin RL, et al: Distribution and Natural History of Stress Fractures in U.S. Marine Recruits. Radiology 146:339-46, 1983. 